\title{
What Does Urban Student Achievement Really Mean beyond Test Scores?
}

\author{
Frederick M. Hampton ${ }^{1}$ \\ ${ }^{1}$ College of Education, Cleveland State University, Cleveland, USA \\ Correspondence: Frederick M. Hampton, Associate Professor of Eduction, College of Education, Cleveland State \\ University, Cleveland, Ohio, USA.
}

Received: December 18, 2015

Accepted: January 12, 2016

Online Published: February 1, 2016

doi:10.5430/irhe.v1n1p136

URL: http://dx.doi.org/10.5430/irhe.v1n1p136

\begin{abstract}
This paper explores important thinking on urban student achievement, and its meaning beyond standardized test scores. Urban school districts often claim victory in the struggle to improve student performance, and frequently tout increased test scores as evidence. However, without corresponding evidence of improvements in students' learner characteristics, e.g., attitudes, behaviors, and skills, the citation of test scores may have little real meaning. This paper seeks to clarify the specific urban learner characteristics that need to be addressed before increased test scores can be considered reliable measures of urban student achievement.
\end{abstract}

Keywords: urban, achievement, motivation, characteristics, school success

In the past 3 years, I've attended many meetings and conferences across the United States that focused on urban student achievement. Although the definition of "urban students" may vary from state to state, it has loosely become a euphemism for non-white, impoverished students in densely populated school districts. In meeting after meeting, I've listened to urban school superintendents and principals tout amazing increases in student achievement, usually in the areas of reading and math. In each case, the dramatic improvements were seemingly correlated with their arrivals as leaders in those positions, and improvements in test scores were offered as evidence to any disbelievers.

It is not my goal to refute their claims. I want to believe that large groups of urban students are making great progress in their academic achievement. I do believe that many urban students can and do make significant progress. But, to paraphrase the late Dr. Carl Sagan, a noted astronomer, "if one is going to make extraordinary claims, one should provide extraordinary evidence." Test scores are important, but they alone are not extraordinary evidence. Furthermore, sudden and dramatic test score increases serve only to raise suspicion regarding the test instrument or the administration of the tests, if not some even far more nefarious explanation.

Occasionally, I've found the opportunity to ask the school administrators more probing questions in an effort to understand the magnificent turnarounds in student performance. I wanted to know what was different, and how things had changed. Was there extraordinary evidence that would lead to the logical conclusion of increased test scores, or were we left to applaud only the magic of smoke and mirrors?

Typically, the rationales provided for the improved student achievement centered on organizational, programmatic, or instructional changes. For example, there may have been the establishment or implementation of Teacher-Based Teams, shared decision making, common planning periods, Professional Learning Communities, Progress Book, Infinite Campus, common assessments, the purchase of Smart Boards for classrooms and I-pads for students, Instructional Rounds, Response to Intervention, and an endless list of other school initiatives.

All of those initiatives clearly have a place in urban schools, and most likely represents money and time well spent. However, those initiatives speak to organizational, programmatic, and instructional changes, which are only half of the academic achievement equation. They do not address the equally important half of the equation, which is "why and how the students have changed?" A more complete understanding of urban student achievement demands that both sides of the equation be addressed. That is when and where the extraordinary evidence might be found. Otherwise, we are left with only purported increases of test scores.

Organizational, programmatic, and instructional initiatives are easily documented. One can quickly obtain records of administrative appointments, staff development sessions, teacher observations, benchmark scores for students, 
meeting agendas, purchase orders, and so forth. However, there is generally little documentation of significant changes in student learner behaviors and characteristics that deepen our understanding of why and how the urban students have improved their academic performance. Yet, there are methods which would allow us to identify and describe the processes of change in student behaviors that lead to the conclusion of improved academic performance. Perhaps more importantly, I believe those characteristics and behaviors can be taught, developed, and nurtured in schools, which would move us closer to a more complete understanding of what urban student achievement really means.

\section{Successful Urban Student Learner Characteristics}

I live and work in Cleveland, Ohio, which not too long ago was described as "the poorest big city in America." According to State Impact Ohio (2015), only 54 percent of the students who entered twelfth grade in Cleveland in the fall of 2008, graduated from high school by spring 2009. In the 2009-10 school year, 40 percent of fifth graders could demonstrate basic, grade-level reading skills, and 29 percent could demonstrate basic, grade-level math skills, according to the district's state report card. For eighth graders, those figures were 61 percent for reading and 41 percent for math.

For many years, I've examined the question of urban student achievement and what it means beyond test scores. Current literature is replete with studies that describe and account for the academic failure of many urban students. I believe that as a practical matter, we know all the conditions and circumstances that lead to that failure. However, my question explores this topic from a different, and I believe a more important perspective. I believe that understanding why some urban students succeed academically is more useful in research than only understanding why others fail.

Every year some Cleveland students survive devastating family, community, and school obstacles, then go on to graduate with honors, and are well prepared to pursue intellectually challenging career options. A few of those students receive full academic scholarships to attend prestigious universities. Others acquire grade point averages and Scholastic Achievement Tests (SAT) scores for traditional acceptance into colleges and universities. And still, some qualify for admittance into community colleges, the armed forces, and to pursue high paying skilled labor apprenticeships.

Almost everyone can think of a friend or acquaintance that overcame tremendously difficult circumstances and became successful in a specific field. We've all heard of individuals who were born into poverty, attended failing schools, were raised by a single parent, and survived tough city streets. Yet, those individuals went on to become some of our most admired citizens. How is this possible? What distinguishes one student from another when neither has familial, economic, or social advantages? Why does one inner city student succeed in school while another fails, yet both are demographically similar? Although we may never completely understand the answers to those questions, the exploration of those questions will move us closer to discovering the extraordinary evidence related to urban student achievement.

My early research in this area began with a qualitative study titled, "The Seven Secrets of Successful Inner City Students" (Hampton, 2008). That study examined the lives of five academically successful seniors from an inner city high school in Cleveland. The search for those students was conducted with the caveat that they had come from impoverished homes, were raised by only one parent, and that parent had no formal education beyond high school. Each of those students overcame tremendously difficult personal and family circumstances. None of the students had been involved with their fathers, all were on public assistance, one of the students had faced homelessness, and others had been in the care of various extended family members. Some of the students had witnessed the effects of drugs on their remaining parent, and all lived in neighborhoods with high drug, crime, and gang activity.

Despite these conditions however, all five of those students demonstrated high academic achievement, and had mapped out promising post-high school careers. Those students had grade point averages that ranged from 3.3 - 4.0. One student had received a full academic scholarship to attend a southern historically black college and another had received a partial academic scholarship to attend a different southern historically black college. Although the remaining three qualified for general college admittance, two deferred entrance for military service and governmental funding for college, which was their long term goal. The last student intended to enroll in a community college to begin a nursing program.

That study revealed the seven most common characteristics among those students which contributed to their academic success. Although in varying degrees, they all shared specific characteristics regarding their attitudes, behaviors, and skills that related to successful learning and achievement. While none of the five students were 
particularly acquainted with the others, those seven characteristics emerged as the most common denominators defining their paths to academic success. Those attitudes, behaviors, and skills became known as their "Successful Learner Characteristics" (SLC) and were identified and defined as follows:

\section{Successful Learner Characteristics}

1) Self Respect - The extent to which the student demonstrates a high regard for him/herself.

2) Command of Standard English - The extent to which the student demonstrates the ability to routinely construct grammatically correct sentences and to pronounce words correctly.

3) Goal Setting Ability - The extent to which the student demonstrates the ability to identify relevant short and long term objectives.

4) Self Motivation - The extent to which the student demonstrates the ability to push him/herself toward the accomplishment of relevant short and long term objectives.

5) Time Management Skills - The extent to which the student demonstrates the ability to plan, organize, schedule, and work on relevant tasks.

6) Consequence Awareness - The extent to which the student demonstrates a concern for the outcomes of his/her actions (to usually think before they act).

7) Respect for Others - The extent to which the student demonstrates regard for the worth, rights, property, and the feelings of others.

Other conditions for urban student achievement have also been discussed in literature such as Resilient Learning, Achievement Motivation, Achievement Values, and Personality Traits. All of these areas are interrelated and interwoven throughout the seven identified Successful Learner Characteristics. When we know more about how urban students acquire, develop, and apply these characteristics and behaviors to learning, we will know more about the meaning of urban student achievement. Perhaps more importantly, we will know more about how to support those students in school and with life skills beyond the K-12 setting.

\section{Resilient Learning}

Some children develop the ability to survive despite many adverse situations in their lives. Those children not only survive, but also thrive academically and socially (Condly, 2006). Many students of color frequently express high aspirations to succeed academically (Fine, 1991; Fordham, 1996; Hauser \& Anderson, 1991; Ogbu, 1990). Yet having abstract desires to succeed is quite different than making the commitment of time and effort to transform the abstract desire into a solid reality.

One area of research that has important implications for the success of students at risk of academic failure is focused on "resilience", or those students who succeed in school despite the presence of adverse conditions. Conceptual and empirical work on resilience has gained recognition as a foundation for examining why some students are successful in school, while other students from the same demographically disadvantaged backgrounds and communities are not (Reis, Colbert, \& Thomas, 2005).

The construct of "educational resilience" should not be viewed as a fixed attribute, but rather as something that can be promoted by focusing on "alterable" factors that can impact an individual's success in school (Benard, 1993). This approach does not focus on attributes such as ability, because ability has not necessarily been found to be a characteristic of resilient students. However, Benard went on to find four personal alterable factors that have been found to influence resiliency in students; social competence, problem-solving skills, autonomy, and a sense of purpose.

Empirical studies indicate that resilient students may approach learning differently from other students: they generally put more effort in their studies and have a higher level of homework completion (Finn and Rock, 1997). They display greater preparation and participation in class work and come to class on time more frequently (Finn and Rock, 1997). They make better use of their time both during and after school hours, they participate more in extracurricular activities (Catterall, 1998) and they display greater engagement in academic activities (Catterall, 1998; Borman and Overman, 2004). Psychologically, resilient students tend to have a higher sense of self-esteem, higher self-efficacy and a greater sense of control over success and failure in school than their non-resilient counterparts ((Borman and Overman, 2004).

Numerous studies on resilience establish a correlation between academic resiliency and academic success, especially in lower socioeconomic populations. For example, a longitudinal study by Scales et al. (2006) found that higher 
levels of resiliency traits are strongly correlated with higher grade point averages among middle and high school students. These findings hold true over time, so that students reporting more resiliency characteristics early in the study had higher GPAs three years later, compared to students with fewer assets at the start.

In studies conducted by the U.S. Department of Education, Waxman and Huang (1997) assessed inner-city students in the south-central United States. They found that students who ranked in the 90th percentile on the standardized tests in mathematics were highly resilient, reporting significantly higher levels of task orientation and satisfaction, social self-concept, achievement motivation, and academic self-concept than their counterparts who ranked below the 10th percentile.

Hanson and Austin (2003) conducted a longitudinal study of students in California and found that nearly every measure of resilience was positively related to concurrent test scores. The highest increases in test scores occurred in schools where the students reported high levels of resilience. Moreover, resilience development proved to be equally beneficial for successive test score improvements in both low and high performing schools.

\section{Achievement Motivation}

Student motivation is an essential element that is necessary for quality education. How do we know when students are motivated? They pay attention, they begin working on tasks immediately, they ask questions and volunteer answers, and they appear to be happy and eager (Palmer, 2007). Theories of achievement motivation have been used to explain achievement behaviors. Generally speaking, achievement motivation has been viewed as an individual's tendency to approach, accomplish, and master various tasks and to rapidly attain high standards (De la Fuente, J., 2004). Motivation orientation has been explained and viewed as either intrinsic or extrinsic with each having a differing effect on academic performance (Harter, 1981).

The underachievement of youth living in poverty is a persistent issue for educators, researchers, and policy makers (Fine, Burns, Payne, \& Torre, 2004; Kozol, 2005). Research on achievement motivation provides some contradicting implications for student academic achievement. Although some studies emphasize achievement motivation as a stable personality trait, others contend that it may be nurtured.

The placement of students into appropriately challenging and supportive learning contexts nurtures intrinsic interest and achievement motivation (Dweck \& Elliott, 1983; Hoekman, McCormick, Cross, \& Miraca 1999). These studies suggested that the achievement and achievement motivation of students may be nurtured in their environment. Whether or not achievement motivation be can be nurtured or is a stable trait, further studies will be needed to explore how culture, specifically, the culture of black students influence its existence.

Perhaps more so than would be expected upon review of national statistics, black students also want to be successful in school, and that notion is confirmed by some research. Garibaldi (1992) surveyed 2,250 black students in schools in New Orleans and found that 95 percent reported that being successful in school was important to them and felt that teachers needed to push them harder to succeed. His research suggests that black students desire to be challenged academically and hold values that pertain to being successful in school. When these students do not experience academic success, they may use coping mechanisms to deal with their feelings about school failure. Their feelings of disappointment may be exhibited through them telling themselves and others that succeeding is not important to them.

The lack of academic success that black students have may be influenced by their school environment and teacher expectations. In cases where students are not encouraged to be successful or educators do not expect them to succeed, they may feel less motivated to achieve. Educators may lower their expectations, and soften the instruction which in turn may have a negative impact on these students' motivation and academic achievement goals (Tucker, 1999).

\section{Achievement Values}

Achievement behavior, based on the research of Solomon (1982), can be defined as a combination of the value placed on achieving by individuals and their subjective probability or expectancy of being successful. On a much broader basis, Bardi \& Schwartz (2003), contend that the relative importance given to achievement values demands that they are ranked as a representation of the value system of an entire social group.

Some research studies have revealed that black students' beliefs, values, and attitudes about achievement has some impact on their academic success. Ford (1996), found that black students' attitudes toward school and achievement orientation significantly influence their achievement behaviors and motivation. According to Sanders (1998), students' achievement ideologies or beliefs about the relationship between schooling future success and prosperity have also been found to influence their academic performance. 
A study by Ford (1994), concluded that academically successful black students strongly supported an achievement ideology and viewed school as important. Moreover, black students were more likely to value academic achievement and educational attainment when they viewed education as an effective means of social and economic improvement. However, they were less likely to place value on academic achievement if they were less optimistic about the role of education for their economic upward mobility.

\section{Personality Traits}

According to McAdams (2008), personality is the sum total of the behavior and mental characteristics that are distinctive of an individual, and develop by adolescence in the form of personal narratives that help to make sense of identity and self. Personality is also described as a categorized set of attributes that is found in a person that influences and defines the individual's cognition, motivations, and behaviors.

Personality traits describe relatively stable patterns of behavior, motivation, emotion, and cognition (Wilt \& Revelle, 2009) that are not bound to a particular socio-cultural context. This does not suggest that every trait will be evident to the same extent in all cultures, nor that every trait can be observed in all situations, but rather that any trait can be observed in a subset of situations in any culture, regardless of time and place. For example, youths vary in their goals and their sense of competence and self-efficiency in particular domains of their lives, e.g., academics and school completion.

Much of the research concerning the impact of personality on achievement of black students centered on low academic achievement of black students in comparison to their white counterparts. There is a dearth of research that focuses on personality development which employs the application of models culturally relevant to black students. Research on personality has been most often based on the Cultural Deprivation and Cultural Difference models. Based on the Cultural Deprivation model, early childhood experiences contribute to enduring personality formation that inhibit academic achievement in black students (Murray, Smith, \& West, 1989).

Some black students have personal traits that foster their academic success. Studies suggest that academically achieving black students appear to share certain personality characteristics. Floyd (1997) examined factors leading to academic success in a group of black high school students. She found that academic success is influenced by the development certain personality traits. Persistence and optimism were identified as personality factors critical to the school success of these students. Participants of the study indicated that they used these personality traits in the face of challenging and stressful school experiences. These students also reportedly exhibited the personality trait of conviction that enabled them to hold a belief that their academic efforts would pay off.

Gordon's (1995) study of academically resilient black high school students revealed that these students exhibited personality traits such sensitivity, sociability, inner control, cooperativeness, cognitive superiority, and biculturality. Ford (1992) conducted a comparative study of achieving and underachieving academically gifted black students. She found that the achieving black students were more likely to hold an internal locus of control than underachieving students. Academically successful students frequently attributed their success to themselves.

\section{Successful Urban Student Learner Characteristics and Achievement}

A quantitative study examined the seven Successful Learner Characteristics and their impact on the academic achievement of students in grades 4-10 (Hampton, 2014). In this research, there was an examination of 157 African-American students to determine if the presence of those characteristics translated into higher academic achievement among students who possessed them. This study was conducted in the Cleveland, Ohio area in multiple schools, classrooms, grade levels, and content areas. For this study, teachers rated students on each of the seven characteristics during mid-semester, then compared earned grades to characteristics at the end of the semester.

Ultimately, this study examined the predictability of students' grades (variable X) when Successful Learner Characteristics (variable Y) were known. And, examined the predictability of Successful Learner Characteristics (variables Y) when students' grades (variable X) were known. Where the correlations between grades and Successful Learner Characteristics is strong, then knowledge of one variable should be highly predictive of the alternative variable.

Over the long term, knowledge of these correlations may prove quite valuable in determining what attitudes, behaviors, and skills should be taught and developed in conjunction with subject content instruction. Theoretically, if improvements can be made in Successful Learner Characteristics, then improvements in students' grades should also be observed over time. 
Table 1. Correlations

\begin{tabular}{|c|c|c|c|c|c|c|c|c|c|}
\hline \multicolumn{10}{|c|}{ Correlations } \\
\hline & & Grade & $\begin{array}{l}\text { Time } \\
\text { Mgmt }\end{array}$ & $\begin{array}{l}\text { Self } \\
\text { Mot }\end{array}$ & $\begin{array}{l}\text { Goal } \\
\text { Setting }\end{array}$ & $\begin{array}{l}\text { Con } \\
\text { Aware }\end{array}$ & $\begin{array}{l}\text { Respect } \\
\text { Others }\end{array}$ & $\begin{array}{l}\text { Self } \\
\text { Respect }\end{array}$ & $\begin{array}{l}\text { Standard } \\
\text { English }\end{array}$ \\
\hline \multirow{8}{*}{$\begin{array}{l}\text { Pearson } \\
\text { Correlation }\end{array}$} & Grade & 1.000 & .810 & .794 & .765 & .596 & .575 & .528 & .500 \\
\hline & Time Mgmt & .810 & 1.000 & .789 & .739 & .596 & .538 & .510 & .490 \\
\hline & Self Mot & .794 & .789 & 1.000 & .844 & .624 & .507 & .553 & .552 \\
\hline & Goal Setting & .765 & .739 & .844 & 1.000 & .589 & .527 & .482 & .538 \\
\hline & Con Aware & .596 & .596 & .624 & .589 & 1.000 & .583 & .589 & .656 \\
\hline & Respect Others & .575 & .538 & .507 & .527 & .583 & 1.000 & .500 & .487 \\
\hline & Self Respect & .528 & .510 & .553 & .482 & .589 & .500 & 1.000 & .502 \\
\hline & Standard English & .500 & .490 & .552 & .538 & .656 & .487 & .502 & 1.000 \\
\hline
\end{tabular}

Table 1 illustrates the correlations among the seven SLC variables as well as their individual, zero-order correlations with grades. As can be seen, the SLC variables are moderately to strongly inter-correlated, ranging from a low of .48 (the correlation between "goal setting" and "self respect", to a high of .84 "goal setting and "self motivation"). The SLC's are also moderately to strongly correlated with grades, "time management" having the highest correlation (.81) and "Standard English" the lowest (.50).

Results of the multiple correlation analysis (with the seven Successful Learner Characteristics as the independent variables and grades, the dependent variable) are presented in Table 2. Fully two thirds (R square $=.67$ ) of the variance in grades is explained by the seven SLC's. This is an unusually high level of predictability and rivals such traditional educational predictors as SES and prior achievement. It is well worth pointing out that the Adjusted R square is virtually identical with the unadjusted $\mathrm{R}$ square, indicating that there would be little reduction in the strength of the relationship upon replication of the study. The important point to note, however, is that academic achievement is here being predicted not by prior achievement (where the correlation would be expected to be high because one is merely a predictor or current achievement from prior achievement), but by attitudes, behaviors, and personal skills.

The seven SLC's also have high internal consistency reliability (Cronbach's alpha $=.91$ ). This is again an unusually high level of reliability for a seven item "test." A principal axes factor analysis adds even further support to these results, with the first factor accounting for approximately $60 \%$ of the total variance, and no factor loading less than .50 .

Table 2. Linear regression

\begin{tabular}{llll} 
Model Summary & & & \\
\hline $\mathrm{R}$ & R Square & Adj. R Square & Std. Error of the Est. \\
0.819 & 0.672 & 0.669 & 0.674 \\
\hline
\end{tabular}

a. Predictors: (Constant), behaviors

Coefficients

\begin{tabular}{ll}
\hline Model & Sig. \\
(Constant) & 0.00 \\
Behaviors & 0.00 \\
\hline
\end{tabular}

a. Dependent Variable: Grade, $\mathrm{p}=0.005$ 
This model is highly reliable and significant, $\mathrm{p}=0.00$. The significant level is 0 . The Adjusted R Square shows that $66.9 \%$ of the variance in academic achievement (as measured by grades) is explained by the seven Successful Learner Characteristics.

\section{Discussion and Next Steps}

The analyses of the seven Successful Learner Characteristics and their influence on the academic achievement of African-American students are both striking and extremely informative. Students who were reported to demonstrate more Successful Learner Characteristics performed higher academically than those students who did not. Although many urban school districts place great emphasis on organizational, programmatic, and instructional changes, no lasting improvements in urban student achievement will take place unless there are corresponding changes in student attitudes, behaviors, and skills. This in total would more completely describe the meaning of urban student achievement and move us closer to establishing extraordinary evidence for improved test scores.

Urban students are not predestined to academic or social failure. High achievement and school success remains well within the grasp of these students given appropriate circumstances and conditions. Most attitudes, behaviors, and skills are learned as a result of interactions with others within one's environment. Moreover, positive attitudes, behaviors, and skills can be further developed and sustained throughout one's life when they are encouraged, nurtured, and reinforced on a consistent basis. I believe that all seven of the Successful Learner Characteristics can be taught, developed, encouraged, and reinforced for urban students in schools and homes, thereby establishing a foundation for greater academic and life success. However, understanding what specific practices, personnel, activities, materials, and conditions that will be necessary for this to take place are still areas that require study.

The Successful Learner Characteristics could be introduced and discussed as early as kindergarten with increasing emphases through grade 12. At all grade levels, these characteristics could be taught and practiced not as a new curriculum, but rather as attitudes, behaviors, and skills that are incorporated as daily expectations of all students. Because the mastery of these characteristics offers benefits to students beyond academic achievement, they could be reinforced and practiced as behavioral expectations in all settings throughout the school day, and supported by parents in the home.

Training faculty members to incorporate the teaching of these characteristics could be accomplished through on site staff development. Faculty members could learn, develop, and share activities which directly correspond to each of the seven Successful Learner Characteristics. Additionally, individual classrooms could become demonstration sites for peer faculty members, and manuals of successful practices could be compiled and organized for distribution. Equally important, the development of a school environment that teaches and encourages these characteristics, then incorporates them as daily expectations should become a significant feature within the school culture.

In the past, our most frequent responses to low student achievement in urban schools have been to intensify end of grade testing, develop more stringent teacher evaluations, and to increase graduation standards. Although those practices are well intentioned, none have led to improved academic outcomes among urban students. All of those endeavors have minimized the most critical factors; the students themselves. Academic achievement is not something that can be inserted into students, accomplished by punitive threats, or purchased for students. Similarly, urban students will not succeed academically when they actively resist learning. In order for those most at-risk of school failure to become successful learners (and thereby successful members of society), they must accept that they share in the responsibility for their own learning and achievement.

The reality for urban students, many of whom are impoverished and at-risk of school failure, is that they must learn to do more with less. These students simply must work harder to achieve than students who have more economic, social, and familial support. However, a more important reality is that when urban students make a commitment to academic excellence, then economic, social, and familial disparities need not be barriers to high achievement.

Regardless of race, family background or economic status, high levels of academic achievement is possible for urban students. For most urban students, school success is not contingent upon innate intelligence or ability, but rather is the result of a well organized academic program, support from the home, a strong desire to learn, and appropriate classroom attitudes, behaviors, and skills that allow learning to take place. I believe that to be the meaning of urban student achievement beyond test scores.

\section{References}

Bardi, A., \& Schwartz, S. H. (2003). Values and behavior: Strength and structure of relations. Personality and Social Psychology Bulletin, 29, 1207-1220. http://dx.doi.org/10.1177/0146167203254602 
Benard, B. (1993). Fostering resilience in kids. Educational Leadership, 51, 44-48.

Borman, G. D., \& Overman, L. T. (2004). Academic resilience in mathematics among poor and minority students. The Elementary School journal, 104(3), 177-195. http://dx.doi.org/10.1086/499748

Catterall, J. S. (1998). Risk and resilience in student transitions to high school. American Journal of Education, 106, 302-333. http://dx.doi.org/10.1086/444184

Condly, S. J. (2006). Resilience in Children: A review of literature with implications for education. Urban Education, 41(3), 211-236. http://dx.doi.org/10.1177/0042085906287902

De la Fuente, J. (2004). Recent perspectives in the study of motivation: Goal orientation theory. Electronic Journal of Research in Educational Psychology, 2(1), 35-62.

Dweck, C. S., \& Elliott, E. S. (1983). Achievement Motivation. In E. M. Hetherington (Ed.), Socialization, Personality, and Social Development. New York: Wiley.

Fine, M. (1991). Framing dropouts. Albany: State University of New York Press.

Fine, M., Burns, A., Payne, Y. A., \& Torre, M. E. (2004). Civics lessons: The color and class of betrayal. Teachers College Record, 106(11), 2193-2223. http://dx.doi.org/10.1111/j.1467-9620.2004.00433.x

Finn, J. D., \& Rock, D. A. (1997). Academic success among students at risk for school failure. Journal of Applied Psychology, 82, 221-234. http://dx.doi.org/10.1037/0021-9010.82.2.221

Floyd, C. (1997). Achieving despite the odds: a study of resilience among a group of African-American high school seniors. Journal of Negro Education, 65(2), 181-189. http://dx.doi.org/10.2307/2967312

Ford, D. Y. (1992). Determinants of underachievement as perceived by gifted, above-average, and average black students. Roeper Review, 14(3), 130-136. http://dx.doi.org/10.1080/02783199209553407

Ford, D. Y. (1994). Nurturing Resilience in Gifted Black Youth. Roeper Review, 17(2), 80-85. http://dx.doi.org/10.1080/02783199409553630

Ford, D. Y. (1996). Reversing underachievement among gifted black students. New York: Teachers College.

Fordham, S. (1996). Blackened out: Dilemmas of Race, Identify, and Success at Capital High. Chicago: University of Chicago Press.

Garibaldi, A. M. (1992). Educating and Motivating African-American Males to Succeed. Journal of Negro Education, 61(1), 4-11. http://dx.doi.org/10.2307/2295624

Gordon, K. A. (1995). Self-Concept and Motivational Patterns of Resilient African-American High School Students. Journal of Black Psychology, 21(3), 239-255. http://dx.doi.org/10.1177/00957984950213003

Hampton, F. M. (2008). The Seven Secrets of Successful Inner City School Students. Retrieved from www.ascd.org/ascd-express/vol3/314-hampton.aspx

Hampton, F. M. (2014). The Seven Secrets of Successful Inner City School Students: The Evidence Continues to Grow. Education and Urban Society, 1-21. Retrieved from eus.sagepub.com

Hanson, T. L., \& Austin, G. (2003). Student health risks, resilience, and academic performance in California: Year 2 report, longitudinal analyses. Los Alamitos, CA: WestEd.

Harter, S. (1981). A Model of Mastery Motivation in Children: Individual Differences and Developmental Change. In W. Collins (Ed.), Minnesota Symposia on Child Psychology (Vol. 140). Hillsdale: Erlbaum.

Hauser, R., \& Anderson, D. (1991). Post high school plans and aspirations of black and white high school seniors: 1976-1986. Sociology of Education, 64, 104-165. http://dx.doi.org/10.2307/2112707

Hoekman, K., McCormick, J., Cross, M., \& Miraca, U. M. (1999). The optimal context for gifted students: A preliminary exploration of motivation and affective consideration. Gifted Child Quarterly, 43(3), 170-193. http://dx.doi.org/10.1177/001698629904300304

Kozol, J. (2005). The shame of the nation: The restoration of apartheid school in America. New York, NY, US: Crown Publishers.

McAdams, D. P. (2008). Personal narratives and the life story. In O.P. John, R.W. Robins, \& Pervin, L.A. (Eds.), Handbook of personality: Theory and Research, (3rd ed., pp. 242-262). New York Guilford. 
Murray, C., Smith, S., \& West, E. (1989). Comparative personality development in adolescence: A critique. In R. Jones (Ed.), Black adolescents (3rd ed., pp. 49-62). Berkeley, CA: Cobb \& Henry.

Ogbu, J. U. (1990). Understanding diversity: Summary comments. Education and Urban Society, 22(4), 425-429. http://dx.doi.org/10.1177/0013124590022004009

Palmer, D. (2007). What is the Best Way to Motivate Students in Science? Teaching Science - The Journal of the Australian Science Teachers Association, 53(1), 38-42.

Reis, S. M., Colbert, R. D., \& Thomas, P. H. (2005). Understanding resilience in diverse, talented students in an urban high school. Roeper Riview, 27(2), 110-129. http://dx.doi.org/10.1080/02783190509554299

Sanders, M. G. (1998). The Effects of School, Family, and Community Support on the Academic Achievement of African-American Adolescents. Urban Education, 3385-409. http://dx.doi.org/10.1177/0042085998033003005

Scales, P. C., Roehlkepartain, E. C., Neal, M., Kielsmeier, J. C., \& Benson, P. L. (2006). The role of developmental assets in predicting academic achievement: A longitudinal study. Journal of Adolesence, 29(5), 692-708. http://dx.doi.org/10.1016/j.adolescence.2005.09.001

Solomon, D. (1982). Theory and research on child achievement. In J. Worell (Ed.), Psychological Development in the Elementary Years (pp. 269-318). New York: Academic Press. http://dx.doi.org/10.1016/B978-0-12-764050-1.50012-8

State Impact Ohio. (2015). Eye on Education. A Reporting Project of NPR. Retrieved from http://stateimpact.npr.org/ohio/tag/cleveland-metropolitan-school-district/

Tucker, C. M. (1999). African-American children: A self-empowerment approach to modifying behavior problems and preventing academic failure. Needleham Heights: Allyn \& Bacon.

Waxman, H. C., \& Huang, S. L. (1997). Classroom instruction and learning environment differences between effective and ineffective urban elementary schools for African American students. Urban Education, 32(1), 7-44. http://dx.doi.org/10.1177/0042085997032001002

Wilt, J., \& Revelle, W. (2009). Extraversion. In M. Leary \& R. Hoyle (Eds.), Handbook of Individual Differences in social Behavior (pp. 27-45). New York: Gilford. 